\title{
Variação sazonal e interanual na dinâmica populacional de Croton blanchetianus em uma floresta tropical seca
}

\author{
Izabelle Silva Nascimento ${ }^{1 *}$, Josiene Maria Falcão Fraga dos Santos ${ }^{1}$, Renata Christina Souza Silva ${ }^{1}$, Danielle Melo dos Santos ${ }^{1}$, \\ Kleber Andrade da Silva², Elcida de Lima Araújo ${ }^{1}$
}

${ }^{1}$ Universidade Federal Rural de Pernambuco, Laboratório de Ecologia Vegetal dos Ecossistemas Naturais, Dois Irmãos, CEP 52171-900, Recife, PE, Brasil 2Universidade Federal de Pernambuco, Laboratório de Biodiversidade, Alto do Reservatório, CEP 55608-680, Vitória de Santo Antão, PE, Brasil

*Autor correspondente:
izabelle.florestal@hotmail.com

Termos para indexação:

Caatinga

Características da população

Regeneração natural

Index terms:

Caatinga

Population characteristics

Natural regeneration

Histórico do artigo:

Recebido em 18/03/2016

Aprovado em 03/09/2017

Publicado em 29/11/2017

doi: 10.4336/2017.pfb.37.92.1191

\begin{abstract}
Resumo - O estudo foi realizado em uma área de caatinga em Pernambuco. Buscou-se avaliar a dinâmica de Croton blanchetianus em função da variação de precipitação entre estações climáticas e entre anos. Todos os indivíduos de C. blanchetianus presentes nas parcelas amostradas foram monitorados mensalmente, durante dois anos consecutivos. Houve diferença significativa de novas plântulas de C. blanchetianus entre estações e entre anos. Considerando a variação de precipitação entre anos, o comportamento da população parece ter sofrido pouca influência, pois apenas 14,8\% de novas plântulas nessa população podem ser explicados pela variação de precipitação entre estações e entre anos. $\mathrm{O}$ poder de explicação da mortalidade pelo modelo linear generalizado foi de $1,4 \%$, considerando a interação entre sazonalidade e variação interanual de precipitação. Diante desse contexto, torna-se necessário uma abordagem mais ampla do ponto de vista ecológico, para avaliar quais fatores ambientais são decisivos e podem estar direcionando o ritmo de renovação dessa população no tempo.
\end{abstract}

\section{Seasonal and interannual dynamic variation of Croton blanchetianus population in a dry tropical forest}

\begin{abstract}
The study was conducted in an area of caatinga in Pernambuco State. and sought to test whether the dynamics of Croton blanchetianus could be correlated with the variation in precipitation between seasons and between years. All individuals of $C$. blanchetianus present in the sampled plots were monitored monthly for two consecutive new seedlings of $C$. blanchetianus between seasons and between years. Considering the variation in rainfall between consecutive years, population seem to have being little influenced, as the generalized linear model (GLM) showed that only $14.8 \%$ of new seedlings in this population can be explained by the variation of precipitation between seasons and between years. In the case of deaths, the explanatory power is $1.4 \%$, considering the interaction between seasonal and interannual variation in rainfall. So, a broader approach from an ecological point of view is necessary to evaluate environmental factors that are decisive, and that could influence the renovation rhythm of this population in time.
\end{abstract}

\section{Introdução}

Diversas florestas do mundo estão sofrendo reduções consideráveis de suas áreas naturais para o estabelecimento de sistemas de agricultura e pastagens (Brando et al., 2016). No Brasil, muitas vezes essas áreas, depois de ocupadas, são abandonadas devido à dificuldade de manutenção das atividades agropastoris (Rocha et al., 2016). Assim, essas áreas reiniciam o processo de regeneração natural, com rebrota ou germinação de sementes que estavam armazenadas 
no solo ou, ainda, diásporos trazidos por dispersores de fragmentos naturais de vegetação localizados em sua proximidade (Lopes et al., 2012; Souza et al., 2014; Mendes et al., 2015). Conhecer a dinâmica de regeneração das populações vegetais que fazem parte desse contexto é um passo imprescindível para responder as lacunas a respeito do processo de regeneração natural, além de base para a condução da restauração. No entanto, existem outros fatores, aliados a este cenário com interferências antrópicas, que precisam ser considerados.

Em escala global, fatores climáticos, como precipitação média anual e sazonalidade climática, podem ser preditores importantes nas taxas de germinação, mortalidade e recrutamento de plantas vasculares e tem sido sugerido que podem afetar, direta ou indiretamente, a densidade de muitos grupos de plantas de florestas tropicais (Gentry, 1991; Schnitzer, 2005) e, consequentemente, o processo de regeneração natural da vegetação. Alguns trabalhos realizados em áreas de florestas secas apontam que o efeito das variaçãoes sazonais e anuais da precipitação podem afetar de forma diferenciada os diferentes estratos da comunidade. Em florestas semiáridas do Brasil, a maior taxa de recrutamento e, consequentemente, maior densidade de plantas do componente herbáceo ocorre em anos com maiores índices pluviométricos. Em anos marcados por baixa precipitação anual há diminuição na taxa de recrutamento, provocada pela baixa taxa de germinação desse componente vegetacional (Reis et al., 2006; Lima et al., 2007; Santos et al., 2013).

Considerando o componente lenhoso, não existe um comportamento padrão definido para todo o grupo. As lianas, por exemplo, são mais bem sucedidas em florestas mais secas, pois as relações entre a precipitação média anual e a densidade são significativamente negativas. A relação entre a duração da estação seca e a densidade desse grupo biológico tem se mostrado significativamente positiva, ou seja, quanto mais longa a estação seca, maior a densidade das lianas (Dewalt et al., 2010).

Por outro lado, Sampaio et al. (1981), com enfoque voltado para uma comunidade lenhosa, encontraram relações positivas entre precipitação e densidade total da vegetação. Em nível populacional, Andrade et al. (2009) também encontraram uma relação positiva entre densidade e precipitação de três espécies arbóreas (Schinopsis brasiliensis Engl., Commiphora leptophloeos (Mart.) J.B. Gillett e Poincianella pyramidalis (Tul.) L.P. Queiroz). Os autores também avaliaram se essa relação permaneceria positiva em populações arbustivas, no entanto, não encontraram essa relação. Essas diferenças nas relações de densidade e precipitação que afetam o comportamento de algumas plantas arbóreas e arbustivas pode indicar que, o hábito das plantas seja uma característica biológica importante para agrupar as populações vegetais na caatinga, mas torna-se necessário que um maior número de espécies seja estudado, a fim de se obter uma avaliação mais consistente desta informação.

Seguindo essa ideia, este trabalho teve como proposta testar a relação da dinâmica (densidade, novas plântulas, mortalidade e sobrevivência) de uma população arbustiva da caatinga com a variação de precipitação. Nossa hipótese é que as variações da dinâmica da população selecionada não são um reflexo das variações nos totais pluviométricos entre estações e entre anos consecutivos. Diante desta expectativa, objetivou-se caracterizar a dinâmica populacional de Croton blanchetianus Baill., em área de caatinga em regeneração natural.

\section{Material e métodos}

\section{Área de estudo}

A pesquisa foi realizada no município de Caruaru, região agreste do Estado de Pernambuco (8¹4'19'S e $35^{\circ} 55^{\prime} 17^{\prime}$ 'W). A área é drenada pelo Riacho Olaria, afluente do Rio Ipojuca e apresenta clima estacional, com precipitação média anual de $710 \mathrm{~mm}$ e temperatura média compensada de $22,7^{\circ} \mathrm{C}$ (Araújo et al., 2005a). As chuvas concentram-se, geralmente, entre os meses de março e agosto, sendo praticamente ausente no restante do período. Por isso, os anos foram considerados de acordo com a sazonalidade climática, sendo o ano I entre março de 2010 a fevereiro de 2011 e o ano II, de março de 2011 a fevereiro de 2012. A precipitação total registrada no ano I foi de $950,6 \mathrm{~mm}(646,2 \mathrm{~mm}$ de chuva concentrados na estação chuvosa, de março a agosto/2010) e no ano II a precipitação total foi de $897,7 \mathrm{~mm}$ (726,8 mm concentrados na estação chuvosa) (Figura 1).

O solo é do tipo Podzólico Amarelo Eutrófico, abrupto a moderado, textura franco-arenosa, fase caatinga hipoxerófila, relevo ondulado a fortemente ondulado (Alcoforado-Filho et al., 2003). O conjunto vegetacional formado nessa região é denominado caatinga de agreste, 
com fisionomia arbórea, também chamada de floresta tropical seca (Araújo et al., 2005a). A área de estudo está inserida na Estação do Instituto Agronômico de Pernambuco $\left(8^{\circ} 14^{\prime} \mathrm{S}\right.$ e $35^{\circ} 55^{\prime} \mathrm{W}, 537 \mathrm{~m}$ de altitude) (Alcoforado-Filho et al., 2003). Essa estação possui 190 ha, que foram inicialmente uma única mancha de vegetação natural de caatinga. Atualmente conta com apenas 20 ha de vegetação natural. De acordo com informantes que moram nas proximidades da estação, antes do seu estabelecimento, há pelo menos 50 anos, essa área era preservada, não sendo permitida a retirada da vegetação lenhosa nem o trânsito de animais domésticos (Santos et al., 2013).

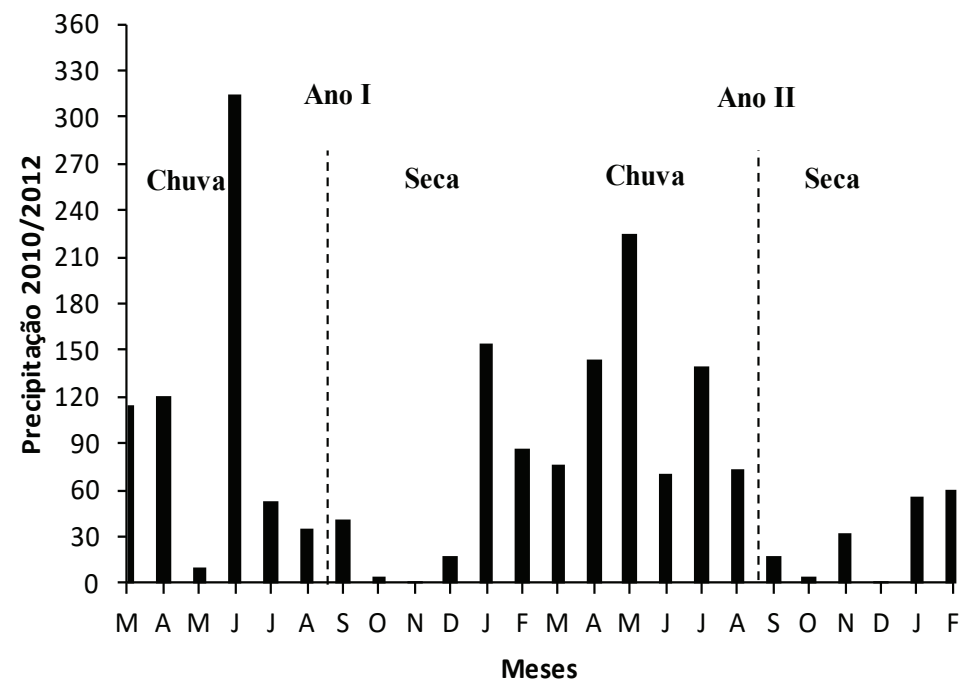

Figura 1. Distribuição da precipitação $(\mathrm{mm})$ durante o período de março de 2010 a fevereiro de 2012, na estação meteorológica do Instituto Agronômico de Pernambuco, em Caruaru, PE.

A área selecionada para este estudo está localizada próxima ao fragmento de caatinga preservada. Essa área, com cerca de 3 ha, sofreu corte raso para o cultivo experimental de Opuntia ficus-indica Mill. (palma doce), que foi abandonado em seguida, estando em processo de regeneração natural há 18 anos. Atualmente, em alguns trechos dessa área antropizada já existem plantas que cresceram e desenvolveram copas, proporcionando uma condição de sombreamento maior ao solo. No entanto, a maioria dos trechos não possui vegetação lenhosa bem desenvolvida e recebe grande insolação durante o período seco e impacto direto das chuvas no período chuvoso. Assim, as plantas do estrato lenhoso formam uma copa descontínua com cerca de $5 \mathrm{~m}$ de altura e o estrato herbáceo é bastante denso, formando um tapete sobre o solo durante o período chuvoso (Lopes et al., 2012; Santos et al., 2013).

A flora lenhosa da área antropizada é representada por espécies como Cordia trichotoma (Boraginaceae), Croton blanchetianus (Euphorbiaceae), Poincianella pyramidalis (Fabaceae), Acacia paniculata (Fabaceae),
Schinopsis brasiliensis (Anacardiaceae), Guapira laxa (Nyctaginaceae) e Piptadenia stipulacea (Fabaceae) (Lopes et al., 2012). A área estudada apresenta ainda uma variação espacial caracterizada pela existência de formações rochosas, além de áreas razoavelmente planas e uma faixa de terreno localizado próximo a um curso d'água temporário, mais evidente no período chuvoso (Santos et al., 2013).

Essa área, com histórico de perturbação antrópica foi selecionada para investigação por se caracterizar como um cenário adequado para estudos que visem compreender como ocorre a dinâmica de populações lenhosas que contribuem para o processo de regeneração natural após a utilização da mesma para fins de agricultura e posterior abandono.

\section{Amostragem da dinâmica e desenvolvimento das plantas}

A espécie selecionada para o estudo foi $C$. blanchetianus, pertencente à família Euphorbiaceae, sendo uma espécie abundante na área selecionada e 
que faz parte da flora permanente de diversas áreas de caatinga (Pereira et al., 2001; Andrade et al., 2005; Santana \& Souto, 2006; Lopes et al., 2012).

Foram estabelecidas, em 2010, um total de 105 parcelas de $5 \mathrm{~m} \times 5 \mathrm{~m}$, distribuídas em sete transectos, com distância de $3 \mathrm{~m}$ entre eles. No interior das parcelas, os indivíduos da espécie selecionada foram marcados, utilizando-se etiqueta plástica e arame plastificado. Entre março de 2010 e fevereiro de 2012 essas parcelas foram monitoradas mensalmente, para registrar o número de plântulas germinadas, mortalidade e sobrevivência da espécie. Os números dados aos indivíduos corresponderam ao momento de seu aparecimento no censo, de forma sequencial.

\section{Análise de dados}

Os dados de todos os indivíduos de C. blanchetianus presentes no interior das parcelas foram organizados em planilha eletrônica, para comparação da população entre diferentes condições climáticas e entre anos e para as análises estatísticas.

A influência da sazonalidade climática na dinâmica da espécie selecionada foi avaliada pelo cálculo das taxas mensais e estacionais de incremento populacional, natalidade e mortalidade. Para tal, foi considerado o número de indivíduos no início da amostragem e o total de novas plântulas e mortes no tempo total de duração de cada mês e estação. As taxas de incremento (r), estabelecimento de novas plântulas (b) e mortalidade (d) da população foram calculadas através do modelo proposto por Swaine \& Lieberman (1987). O poder de explicação das variações sazonais e anuais da precipitação sobre o número de novas plântulas e mortalidade foi avaliado usando o modelo linear generalizado (GLM) e as diferenças sazonais e anuais nos números de novas plântulas e mortes médios foram verificadas pelo teste de Tukey a posteriori com $\mathrm{p}<0,05$ (Zar, 1996). A análise foi realizada pelo Statistica 7.0. Para avaliar diferenças no estabelecimento de novas plântulas e mortalidade da população de $C$. blanchetianus, entre estações climáticas e entre anos, foi utilizado o teste de Kruskall-Wallis com o auxílio do programa Bioestat 5.0 (Ayres et al., 2007). A sobrevivência da população estudada foi descrita através dos percentuais de indivíduos sobreviventes das coortes no início do estudo.

\section{Resultados}

Durante o período chuvoso dos anos I e II (março a agosto), a densidade da população de Croton blanchetianus variou, respectivamente, de 4.191 a 4.309 ind ha $^{-1}$ e 4.767 a 5.572 ind ha ${ }^{-1}$ (Figura 2). No período seco (setembro a fevereiro), a densidade populacional da espécie variou de 3.998 a 5.732 ind ha ${ }^{-1}$ e 4.358 a 4.659 ind $\mathrm{ha}^{-1}$, nos anos I e II, respectivamente (Figura 2).

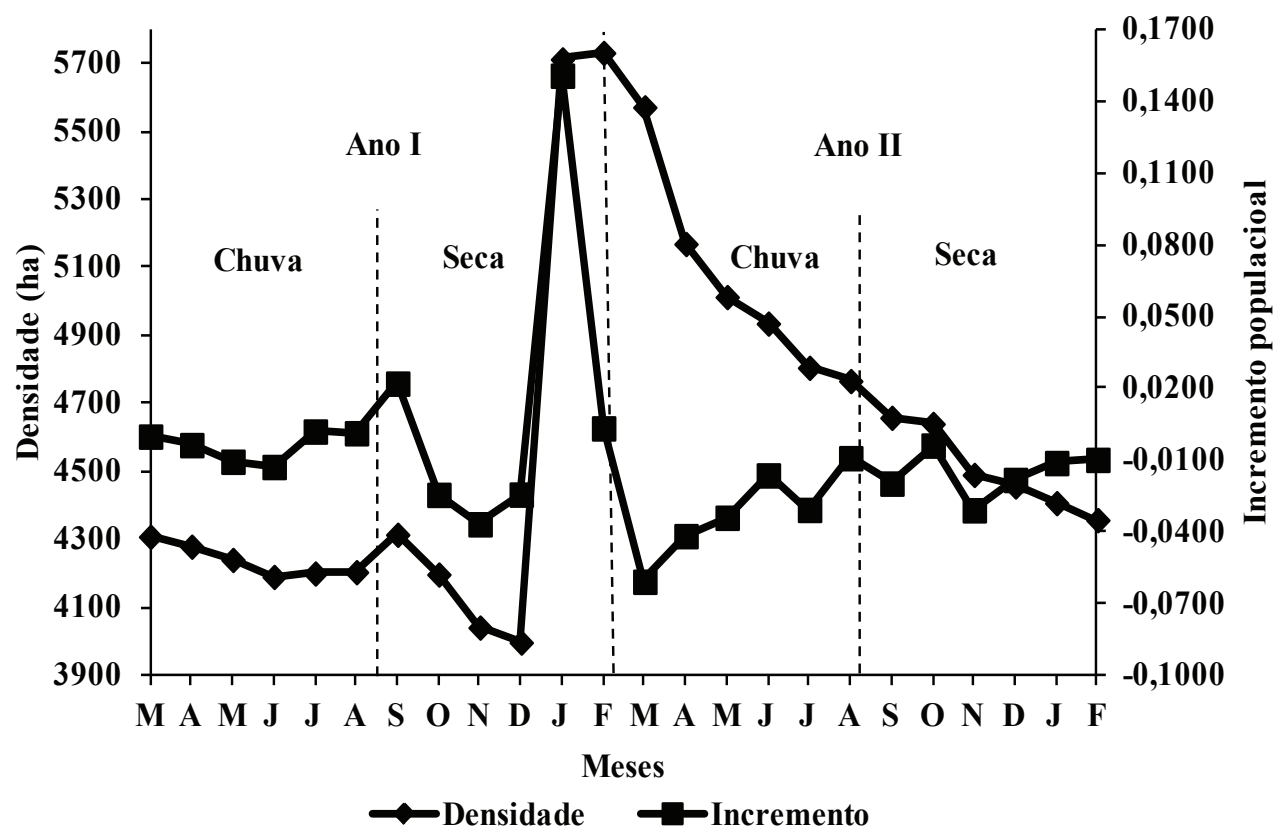

Figura 2. Densidades mensais (ind ha ${ }^{-1}$ ) e incremento populacional [ind.(ind mês) ${ }^{-1}$ ] de Croton blanchetianus, no período de março de 2010 a fevereiro de 2012, em uma área de caatinga antropizada em Pernambuco. 
Quanto ao ingresso de novas plântulas, no primeiro ano de monitoramento foi registrada uma taxa acumulada de 0,2212 novos ind mês ${ }^{-1}$ e no ano II essa taxa foi de 0,0317 novos ind mês ${ }^{-1}$ (Figura 3 ). De acordo com o teste do modelo linear generalizado (GLM), a variação interanual exerceu uma influência de 11,3\% no ingresso de novas plântulas. No entanto, a interação entre a sazonalidade e variação anual exerceu uma influência muito inferior (1,6\% no ingresso de novas plântulas). Houve diferença significativa no ingresso de novos indivíduos de $C$. blanchetianus entre anos (Z(U) $=5,2636 ; \mathrm{p}=0,0001$ ).

Houve registro de ingresso de novas plântulas durante toda a estação chuvosa do ano I e em praticamente toda a estação chuvosa do ano II, com exceção do mês de junho. Na estação seca, taxas de ingresso não foram verificadas nos meses de novembro e dezembro do ano I e outubro e dezembro do ano II. Porém, em janeiro da estação seca do ano I foi registrado um pico de novos ingressos de plântulas (Figura 3).

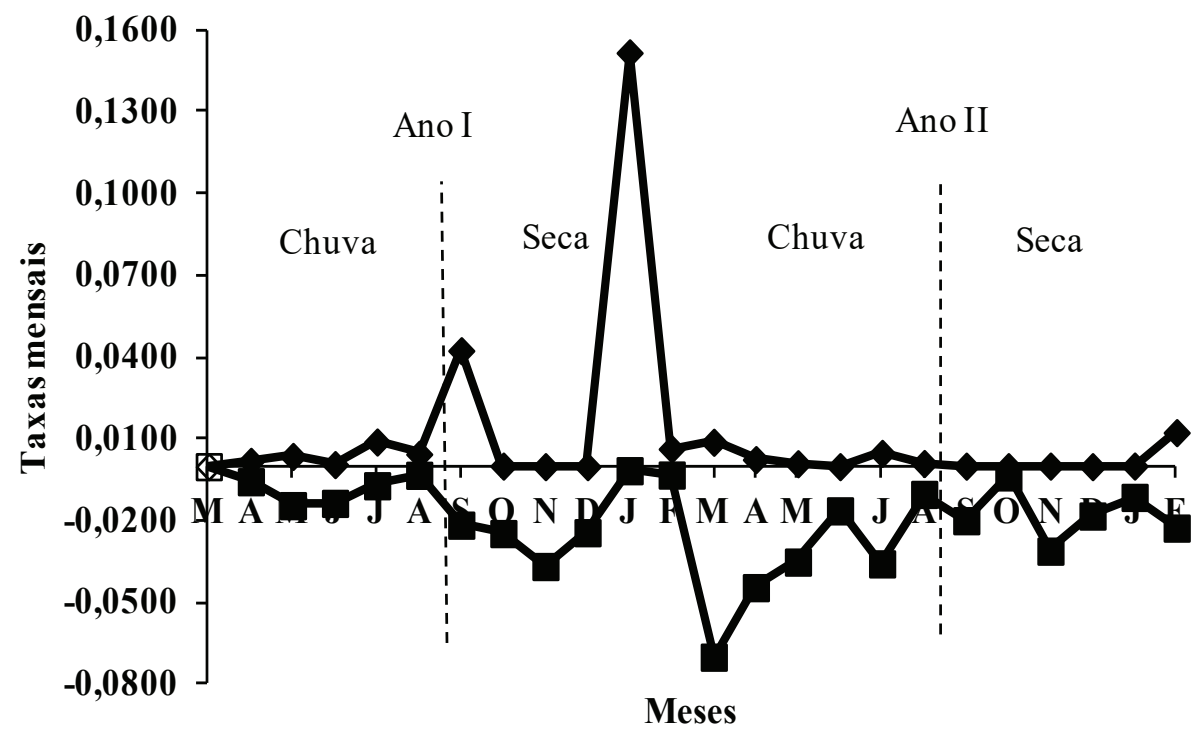

$\sim$ Natalidade $\rightarrow$ Mortalidade

Figura 3. Taxas mensais de ingresso [novos ind $\mathrm{mê}^{-1}$ ] e mortalidade [ind mês $\left.{ }^{-1}\right]$ de Croton blanchetianus, no período de março de 2010 a fevereiro de 2012, em uma área de caatinga antropizada em Pernambuco.

A sazonalidade climática respondeu a apenas 1,8\% do ingresso de novas plântulas na população (Tabela 1). Houve diferença significativa no ingresso de plântulas de $C$. blanchetianus entre as estações seca e chuvosa do ano $\mathrm{I}(\mathrm{Z}(\mathrm{U})=2,6676 ; \mathrm{p}=0,0038)$ e do ano II $(\mathrm{Z}(\mathrm{U})=$ 2,0952; $\mathrm{p}=0,0181$ ).

O total acumulado da taxa de mortalidade no ano I foi $-0,1549$ ind ês $^{-1}$ e no ano II $-0,3180$ ind mês $^{-1}$ Em todos os meses monitorados houve registro de mortalidade. Os menores picos na taxa de mortalidade ocorreram em janeiro do ano I e outubro do ano II (Figura 3). De acordo com o teste GLM, a variação entre anos parece exercer baixa influência na mortalidade da população $(1,6 \%)$.

A interação entre a sazonalidade e a variação interanual entre os totais de chuvas respondeu a $1,4 \%$ dos ingressos de novas plântulas na população. Não houve diferença significativa para mortalidade de $C$. blanchetianus entre anos $(\mathrm{Z}(\mathrm{U})=0,1851 ; \mathrm{p}=0,4266)$.

Taxas de mortalidade foram verificadas durante toda a estação chuvosa tanto do ano I quanto no ano II, com picos registrados nos meses de novembro do ano I e março do ano II. Essas taxas também foram registradas durante toda a estação seca, para os dois anos (Figura 3). As variações sazonais nos totais de chuva não responderam as mortes que ocorreram na população de $C$. blanchetianus, de acordo com o teste GLM, ou seja, não houve influência da sazonalidade climática na mortalidade da população estudada (Tabela 2). Houve diferença significativa na mortalidade de $C$. blanchetianus entre as estações seca e chuvosa do ano I 
$(\mathrm{Z}(\mathrm{U})=3,1343 ; \mathrm{p}=0,0009)$, porém não houve diferença significativa entre as estações seca e chuvosa do ano II $(\mathrm{Z}(\mathrm{U})=1,164 ; \mathrm{p}=0,1222)$.

A variação mensal na taxa de incremento de $C$. blanchetianus nos dois anos foi semelhante (Figura 2), sendo negativa na maioria dos meses. No entanto, em nenhum mês essa taxa foi nula. O total acumulado da taxa de incremento no ano I foi 0,0679 ind mês $^{-1}$ e no ano II foi 0,2852 ind mês $^{-1}$. A maior taxa de incremento foi de 0,15 ind mês ${ }^{-1}$ e a menor foi de $-0,06$ ind mês ${ }^{-1}$, que correspondem à estação seca do ano I e chuvosa do ano II, respectivamente.

A taxa de incremento populacional da espécie foi negativa na estação chuvosa do ano I nos meses de abril, maio e junho, enquanto que na mesma estação do ano seguinte essa taxa foi negativa em todos os meses. Durante a estação seca do primeiro ano, a taxa de incremento foi negativa em outubro, novembro e dezembro e no ano seguinte foi negativa em todos os meses da estação seca (Figura 2).

Tabela 1.Variação sazonal e anual no ingresso médio de novas plântulas na população de Croton blanchetianus em uma área de caatinga antropizada em Pernambuco.

\begin{tabular}{|c|c|c|c|c|c|c|}
\hline \multirow[t]{2}{*}{ Ano } & \multirow[b]{2}{*}{ Estações } & \multirow[b]{2}{*}{ Ingresso Médio } & \multicolumn{2}{|c|}{1} & \multirow{2}{*}{$\begin{array}{c}2 \\
\text { Chuva }\end{array}$} & \multirow{2}{*}{ 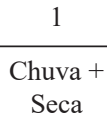 } \\
\hline & & & Chuva & Seca & & \\
\hline \multirow[t]{2}{*}{1} & Chuva & 42 & - & - & - & - \\
\hline & Seca & 19 & 0,000861 & - & - & - \\
\hline \multirow[t]{2}{*}{2} & Chuva & 1 & 0,000008 & 0,019221 & - & - \\
\hline & Seca & 1 & 0,000008 & 0,014239 & 0,999670 & - \\
\hline 1 & Chuva + seca & 30 & - & - & - & - \\
\hline 2 & Chuva + seca & 1 & - & - & - & 0,000009 \\
\hline
\end{tabular}

Matriz triangular com a significância; valores em negrito denotam diferença significativa entre estações climáticas e entre anos pelo teste de Tukey a posteriori $(\mathrm{p}<0,05)$.

Tabela 2. Variação sazonal e anual na mortalidade média da população de Croton blanchetianus em uma área de caatinga antropizada, em Pernambuco.

\begin{tabular}{|c|c|c|c|c|c|c|}
\hline \multirow[t]{2}{*}{ Ano } & \multirow[b]{2}{*}{ Estações } & \multirow[b]{2}{*}{$\begin{array}{l}\text { Mortalidade } \\
\text { média }\end{array}$} & \multicolumn{2}{|c|}{1} & \multirow{2}{*}{$\begin{array}{c}2 \\
\text { Chuva }\end{array}$} & \multirow{2}{*}{$\frac{1}{\text { Chuva }+ \text { Seca }}$} \\
\hline & & & Chuva & Seca & & \\
\hline \multirow[t]{2}{*}{1} & Chuva & 1,83 & - & - & - & - \\
\hline & Seca & 4,31 & 0,697635 & - & - & - \\
\hline \multirow[t]{2}{*}{2} & Chuva & 9,96 & 0,002070 & 0,063254 & - & - \\
\hline & Seca & 4,54 & 0,635013 & 0,999639 & 0,081239 & - \\
\hline 1 & Chuva + seca & 3,07 & - & - & - & - \\
\hline 2 & Chuva + seca & 7,25 & - & - & - & 0,009970 \\
\hline
\end{tabular}

Matriz triangular com a significância; os valores em negrito denotam diferença significativa entre estações climáticas e entre anos pelo teste de Tukey a posteriori $(\mathrm{p}<0,05)$.

Quanto à sobrevivência de C. blanchetianus, no primeiro ano, considerando a primeira coorte, com 4.309 indivíduos, $76 \%$ conseguiram sobreviver durante todo o monitoramento. No segundo ano de monitoramento, esse percentual foi de $42 \%$, ou seja, de 24 indivíduos pertencentes à primeira coorte, apenas 10 permaneceram vivos até o final do estudo (Figura 4).

Considerando a sobrevivência dentro das estações climáticas, mais de $95 \%$ da primeira coorte da estação chuvosa do ano I permaneceram vivos até o final da estação. E, dos indivíduos que ingressaram na primeira coorte da estação seca deste mesmo ano, 91\% atingiram o final da estação. No ano II, da coorte dos indivíduos que ingressaram no início da estação chuvosa, 58\% permaneceram vivos até o final da estação e todos aqueles que ingressaram no início da estação seca $(100 \%)$ permaneceram vivos até o final da estação (Figura 4). 


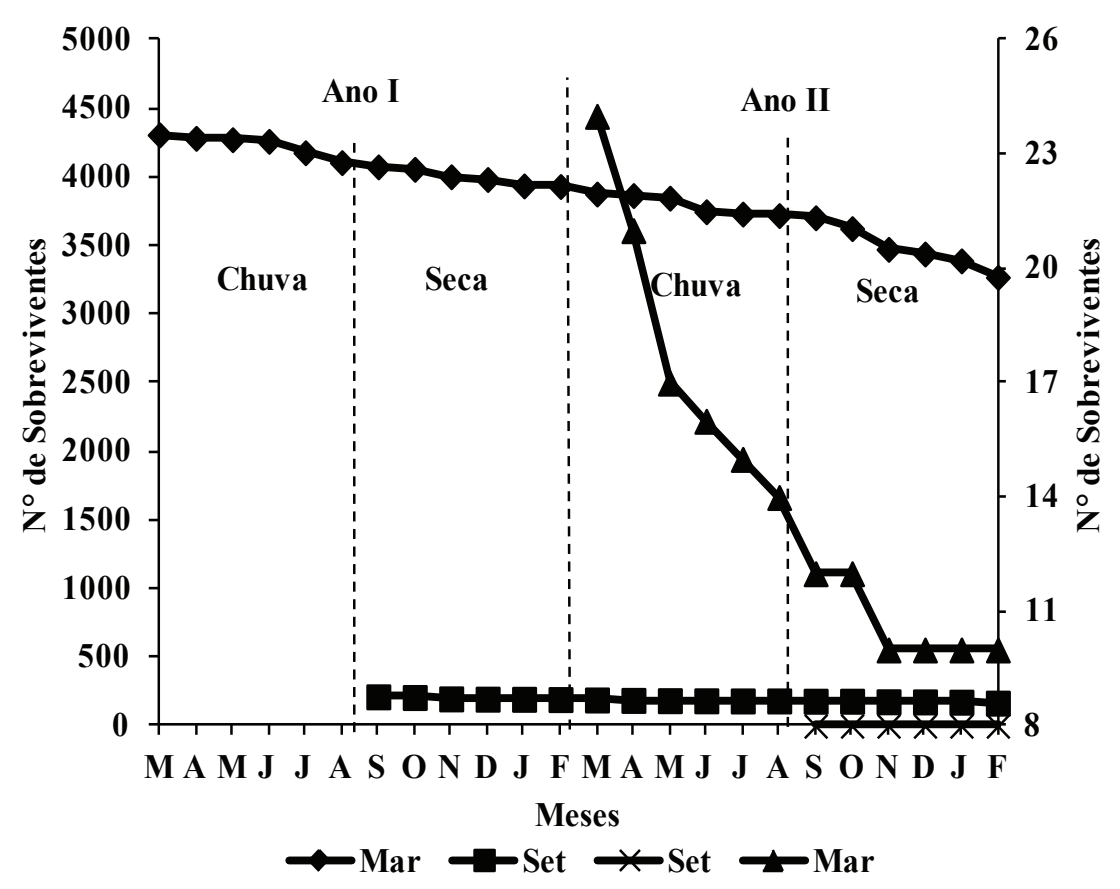

Figura 4. Variações na curva de sobrevivência de Croton blanchetianus considerando as estações chuvosa e seca em uma área de caatinga antropizada em Pernambuco.

\section{Discussão}

Na caatinga, a sazonalidade climática é um fator ambiental que afeta o comportamento da vegetação como um todo, pois é sabido que durante a estação seca muitas plantas lenhosas exibem a caducifolia, contribuindo com a fisionomia de vegetação seca (Andrade-Lima, 1992), além de uma baixa densidade de plantas herbáceas anuais, que não suportam a escassez hídrica (Reis et al., 2006; Santos et al., 2009, 2013; Silva et al., 2011). No entanto, durante a estação chuvosa há uma exuberância na fisionomia, uma vez que as plantas lenhosas voltam a emitir folhas novas, florescer e frutificar (Andrade-Lima, 1992) e ainda à riqueza da comunidade vegetal são somadas as herbáceas, que aumentam consideravelmente suas densidades nessa estação (Reis et al., 2006; Clary, 2008).

No entanto, considerando a espécie arbustiva Croton blanchetianus, selecionada neste estudo como modelo para testar a hipótese, a variação nos totais de chuvas que ocorrem entre as estações climáticas parece não ser um fator que determine o comportamento biológico da população, pois não existe uma relação direta entre precipitação e dinâmica desse arbusto em curto prazo, possivelmente existindo outros fatores que sejam mais importantes. Nesse contexto, esse fator é nulo, ou seja, não explica as taxas de mortalidade observadas. Isso significa que a hipótese levantada neste trabalho foi confirmada, já que as análises realizadas demonstraram que a variação na precipitação não responde de forma satisfatória à dinâmica de ingresso e mortalidade, que reflete a densidade das populações.

Por outro lado, em médio prazo, ou seja, passando a considerar uma variação nos totais pluviométricos entre anos consecutivos, o comportamento de C. blanchetianus parece receber alguma influência, embora baixa, pois o modelo linear generalizado (GLM) demonstrou que apenas cerca de $14,8 \%$ dos nascimentos nessa população pode ser explicado pela soma desses fatores (variação da precipitação entre estações e entre anos consecutivos). No caso das mortes, o poder de explicação é ainda mais reduzido $(1,4 \%)$, considerando a interação entre sazonalidade e variação interanual na precipitação.

É possível que características intrínsecas à espécie também sejam responsáveis pelo comportamento dinâmico dessa população, como, por exemplo, o próprio hábito arbustivo de $C$. blanchetianus, como já sugerido por alguns autores (Sampaio et al., 1981; Andrade et al., 2009). Algumas espécies utilizadas como modelo em estudos dessa natureza têm demostrado que 
características estruturais de certos grupos vegetacionais podem exibir padrões ou tendências diferenciadas de reprodução e/ou dinâmica das populações (Crawley, 1989; Andrade et al., 2009). No entanto, na vegetação da caatinga, as causas de tais variações são pouco discutidas e comparadas em nível populacional. Muito embora a disponibilidade de água seja um dos fatores considerados de grande influência na estrutura das populações e organização das comunidades vegetais, sobretudo para populações que exibem padrões de atividades biológicas fortemente influenciadas pelos ritmos sazonais (Machado et al., 1997; Barbosa, 2002; Barbosa et al., 2003; Araújo et al., 2005a, 2008; Lima et al., 2007; Araújo, 2008), provavelmente outros fatores ambientais estão regulando a dinâmica de $C$. blanchetianus na área de estudo.

As características nas condições de estabelecimento no interior das florestas vêm sendo apontada como um fator de grande relevância, que determina não apenas a distribuição de uma espécie e estrutura, mas também a dinâmica de suas populações (Reis et al., 2006; García-Cháves et al., 2014; Silva et al., 2016). A área de estudo possui uma elevada diversidade nas condições de estabelecimento que, associado à variação na precipitação, pode exercer uma influência de maior expressão sobre a dinâmica de $C$. blanchetianus. A proximidade com o curso de um riacho ou a presença de afloramentos rochosos dentro da floresta, por exemplo, são características que podem auxiliar as populações de plantas a se manterem por mais tempo, sobretudo nos estádios iniciais do seu desenvolvimento. Essas condições favorecem a retenção de água por um período maior no local e aumentam a disponibilidade temporal desse recurso para absorção das plantas.

Em nível de comunidade, estudos têm mostrado que as características dos solos influenciam a presença de espécies, o porte e a densidade das plantas (Sampaio et al., 1981; Araújo et al., 2005b; Reis et al., 2006). Entretanto, esse tipo de estudo também seria interessante em nível de população, pois é bastante provável que características físico-químicas dos solos também influenciem a estrutura das populações entre os habitats (García-Cháves et al., 2014) embora, em áreas de caatinga, tais relações ainda não foram realizadas.

Vale salientar que, em condição natural, as populações vegetais estão interagindo com diversas variáveis bióticas e abióticas que estão sujeitas a mudanças temporais (Crawley, 1989; Reis et al., 2006; Lima et al., 2007). Em ambientes com histórico de perturbação intensa, as interações entre essas variáveis podem ser intensificadas. No entanto, para conhecermos melhor as respostas das populações lenhosas que fazem parte da regeneração das florestas de caatinga, são necessários estudos em escala temporal maior. Além disso, é importante considerar a diversidade nas condições de estabelecimento, característica marcante na caatinga, para que análises possam avaliar o efeito interativo desses fatores sobre a dinâmica de populações lenhosas.

\section{Conclusão}

Este estudo mostra que as variações interanuais e sazonais não são responsáveis diretas pelas variações na população de Croton blanchetianus. Entretanto, é possível que características da própria espécie ou condicionada a outros fatores ambientais sejam responsáveis pelas variações na sua dinâmica, com interferência em sua estrutura populacional. Contudo, torna-se necessário um período ainda maior de estudo e uma abrangência desse tema em outras áreas de caatinga, para que se possam obter respostas mais conclusivas quanto aos fatores atuantes na dinâmica populacional dessa espécie.

\section{Agradecimentos}

Ao Conselho Nacional de Desenvolvimento Científico e Tecnológico (CNPq), pela concessão de bolsas, ao Instituto Agronômico de Pernambuco (IPA). À Universidade Federal Rural de Pernambuco (UFRPE), pelo apoio logístico; e aos pesquisadores do Laboratório de Ecologia Vegetal de Ecossistemas Naturais (LEVEN), pelo apoio. À Coordenação de Aperfeiçoamento de Pessoal de Nível Superior (CAPES), pela concessão de bolsa de pós-doutorado - PNPD/processo: 23038.008230/2010-75 a Josiene Santos.

\section{Referências}

Alcoforado-Filho, F. G. et al. Florística e fitossociologia de um remanescente de vegetação caducifólia espinhosa arbórea em Caruaru, Pernambuco. Acta Botânica Brasílica, v. 17, n. 2, p. $287-$ 303, 2003. DOI: 10.1590/S0102-33062003000200011.

Andrade-Lima, D. O domínio das caatingas. Recife: UFRPE: IPA; Brasília, DF: CNPq, 1992. 
Andrade, L. A. et al. Análise da cobertura de duas fitofisionomias de Caatinga, com diferentes históricos de uso, no município de São João do Cariri, Estado da Paraíba. Cerne, v. 11, n. 3, p. 253-262, 2005.

Andrade, W. M. et al. Influência da precipitação na abundância de populações de plantas da Caatinga. Revista de Geografia, v. 26, n. 2, p. 161-184, 2009.

Araújo, E. L. Características florísticas e ecológicas da vegetação da caatinga: atualidades e desafios. In: CONGRESSO NACIONAL DE BOTÂNICA, 59; REUNIÃO NORDESTINA DE BOTÂNICA, 31; CONGRESSO LATINO-AMERICANO DE CACTACEAE E OUTRAS SUCULENTAS, 4.; CONGRESSO DA ORGANIZAÇÃO INTERNACIONAL PARA O ESTUDO DAS PLANTAS SUCULENTAS, 31., 2008, Natal. Atualidades, desafios e perspectivas da botânica do Brasil: anais. Natal: UFERSA: UFRN: SBB, 2008. p. 171-174.

Araújo, E. L. et al. Diversidade de herbáceas em microhabitats rochoso, plano e ciliar em uma área de caatinga, Caruaru- PE. Acta Botânica Brasílica, v. 19, n. 2, p. 285-294, 2005b.

Araújo, E. L. et al. Ecofisiologia de plantas da caatinga e implicações na dinâmica das populações e do ecossistema. In: Moura, A. N. et al. (Ed.). Biodiversidade, potencial econômico e processos ecofisiológicos em ecossistemas nordestinos. Recife: Comunigraf, 2008. p. 329-361.

Araújo, E. L. et al. Establishment and death of two dry tropical forest woody species in dry rainy seasons in northeastern Brazil. In: Nogueira, R. J. M. C. et al. (Ed.). Estresses ambientais: danos e benefícios em plantas. Recife: Imprensa Universitária da UFRPE, 2005a. p. 76-91.

Ayres, M. et al. A. BIOESTAT: aplicações estatísticas nas áreas das ciências bio-médicas. Belém: Sociedade Civil Mamirauá, 2007.

Barbosa, D. C. A. Estratégias de germinação e crescimento de espécies lenhosas da caatinga com germinação rápida. In: Leal, I. et al. (Ed.). Ecologia e conservação da caatinga. Recife: Universidade Federal de Pernambuco, 2002. p. 625-656.

Barbosa, D. C. A. et al. Fenologia de espécies lenhosas da caatinga. In: Leal, I. F. et al. (Ed.) Ecologia e conservação da caatinga. Recife: Universidade Federal de Pernambuco, 2003. p. 657-693.

Brando, P. et al. Climate impacts of expanded soy agriculture in the arc of deforestation in Brazil. Geophysical Research Abstracts, v. 18, p. 1-10, 2016.

Clary, J. Rainfall seasonality determines annual/ perennial grass balance in vegetation of Mediterranean Iberian. Plant Ecology, v. 195, p. 13-20, 2008. DOI: 10.1007/s11258-007-9294-9.

Crawley, M. J. Life History and environment. In: Grawley, M. J. (Ed.). Plant ecology. Oxford: Blackwell Scientific Publications, 1989. p. 253-290.

Dewalt, S. J. et al. Annual rainfall and seasonality predict pan-tropical patterns of liana density and basal area. Revista Biotropica, v. 42, n. 3, p. 309-317, 2010. DOI: 10.1111/j.1744-7429.2009.00589.x.

García-Cháves, J. H. et al. The relative importance of solar radiation and soil origin in cactos seedling survivorship at two spatial scales: plant association and microhabitat. Journal of Vegetation Science, v. 25, n. 3, p. 668-680, 2014. DOI: 10.1111/jvs.12139.
Gentry, A. H. The distribution and evolution of climbing plants. In: Putz, F. E. \& Mooney, H. A. (Ed.). The biology of vines. Cambridge: Cambridge University Press, 1991. p. 3-49.

Lima, E. N. et al. Fenologia e dinâmica de duas populações herbáceas da Caatinga. Revista de Geografia, v. 24, n. 1, p. 120-136, 2007.

Lopes, C. G. R. et al. Forest succession and distance from preserved patches in the Brazilian semiarid region. Forest Ecology and Management, v. 271, p. 115-123, 2012. DOI: 10.1016/j. foreco.2012.01.043.

Machado, I. C. et al. Phenology of caatinga species at Serra Talhada, PE, Northeastern Brazil. Biotropica, v. 29, p. 57-68, 1997. DOI: 10.1111/j.1744-7429.1997.tb00006.x.

Mendes, L. B. et al. What happens to the soil seed bank 17 years after clear cutting of vegetations?. Revista de Biologia Tropical, v. 63, n. 2, p. 321-332, 2015. DOI: 10.15517/rbt.v63i2.14683.

Pereira, I. M. et al. M. Regeneração natural em um remanescente de Caatinga sob diferentes níveis de perturbação, no Agreste Paraibano. Acta Botânica Brasílica, v. 15, n. 3, p. 413-426, 2001. DOI: 10.1590/ S0102-33062001000300010.

Reis, A. M. S.et al. Inter-annual variations in the floristic and population structure of an herbaceous community of "caatinga" vegetation in Pernambuco, Brazil. Revista Brasileira de Botânica, v. 29, n. 3, p. 497-508, 2006. DOI: 10.1590/S010084042006000300017.

Rocha, G. P. E. et al. Fast natural regeneration in abandoned pastures in southern Amazonia. Forest Ecology and Management, v. 370, p. 93-101, 2016. DOI: 10.1016/j.foreco.2016.03.057.

Sampaio, E. V. S. B. et al. Gradiente vegetacional das caatingas e áreas anexas. Revista Brasileira de Botânica, v. 4, p. 27-30, 1981.

Santana, J. A. S. \& Souto, J. S. Diversidade e estrutura fitossociológica da Caatinga na Estação Ecológica do Seridó-RN. Revista de Biologia e Ciências da Terra, v. 6, n. 2, p. 232-242, 2006.

Santos, J. M. F. F. et al. Dinâmica de duas populações herbáceas de uma área de Caatinga, Pernambuco, Brasil. Revista de Geografia, v. 26, n. 2, p. 142-160, 2009.

Santos, J. M. F. F. et al. Natural regeneration of the herbaceous community in a semiarid region in Northeastern Brazil. Environmental Monitoring and Assessment, v. 185, n. 1, 2013. DOI: $10.1007 / \mathrm{s} 10661-013-3173-8$.

Schnitzer, S. A. A mechanistic explanation for global patterns of liana abundance and distribution. The American Naturalist, v. 166, p. 262-276, 2005.

Silva, K. A. et al. The influence of microhabitat on the population dynamics of four herbaceous species in a semiarid area of northeastern Brazil. Brazilian Journal of Biology, v. 76, n. 1, p. 45-54, 2016. DOI:10.1590/1519-6984.10014.

Silva, R. C. S. et al. Dinâmica de Delilia biflora kuntze sob a influência da sazonalidade climática e diferentes status de conservação em uma floresta seca do Brasil. Revista de Geografia, v. 28, n. 2, p. 132-148, 2011.

Souza, J. T. et al. Does proximity to a mature forest contribute to the seed rain and recovery of an abandoned agriculture area in a semiarid climate? Plant Biology, v. 16, p. 748-756, 2014. DOI: 10.1111/plb. 12120 . 
Swaine, M. D. \& Lieberman, D. Note on the calculation of mortality rates. Journal of Tropical Ecology, v. 3, 1987.
Zar, J. H. Bioestatistical analysis. Ney Jersey: Prentice Hall, 1996. 